\title{
Water leak detection method in water distribution network
}

\author{
Ahmad Fuad Z. ${ }^{1}$, Eddy H. S. ${ }^{*}{ }^{1}$ Badronnisa Y. ${ }^{2}$ and Syazwani I. ${ }^{2}$ \\ ${ }^{1}$ Student Civil Engineering Department, Faculty of Engineering, UPM \\ ${ }^{2}$ Lecturer Civil Engineering Department, Faculty of Engineering, UPM \\ *eddyherman01@gmailcom
}

\begin{abstract}
Leakages attribute to one of major component of which is of major problems in water industry. Today water leakages issued are listed in top priority in many water operator worlds widely. This study provides review of the leak detection method and technology. Leakages cause a massive cost economically and operationally. Leakages also a sign of water operator operationally efficiency. Therefore, this topic has attracted a lot of attention by the academician researcher or water industry expertise over the past years to study and lastly to invent latest technology is ease operation. In need to find the fast result and economical to determine the leakage. There are many methods to detect a leakage such as sound, acoustic, vibration, sensor, pressure, etc. We herewith studied as many useful research papers in this field and trying to address the available method to detect the leakages. Leakages will lead numeral of customer's complaint and will reflect negative perspective of water operator operational efficiency. Hence, consumers are being the sensor to leakages that happens throughout the networks. Current technology integrated with the engineering principle, using sensors to monitor distribution networks are most recommended method and will ease the monitoring of water network systems. Real time-based sensors will notify any incidence and the algorithm will forecasted leakages before the its been visualised and notified. In this review shall include the real time-based leak detection method and wireless water network technology for references.
\end{abstract}

\section{Introduction}

Efficient management is an important part of the water distribution network in reducing losses [1]; High water loss will threaten our water resources and increase the cost of water service providers. Failure to deal with this problem caused anxiety to the public, the researchers and the government as well. The loss is recorded at 500 million a year [2].

Leakage in urban water distribution facing a challenge to maintain the sustainability. In most water distribution network, the production cost and operational cost need to be in tandem. Hence, the efficient of maintaining the leakages is out most important. These losses will cause a huge revenue loses and the water reserve margin nationally. The leakage provides $50 \%$ of losses in water distribution [3] which one the major component of Non-Revenue Water (NRW). This component is namely as physical loses of the water supply network and impacting both the economy and the environment. Commonly leakages happen along the distribution network from the water treatment plant to water distribution network until it reaches the consumers.

Leakages shall describe in two components which are commercial losses and physical losses. Meter faulty, water theft and inefficient billing to consumers are categorised as commercial losses. Physical loses can describes as flushing activities, pipe burst or leak and fire fighting activities. Nevertheless, 
this review paper describes the leakage is the major cause. This component of leakages occurs in many ways, situation, location and caused. The leakages are mainly occurring in water distribution network due to the condition of the network material and age. Most of the study shown leakages happen at the jointing of the water distribution network. Water hammering, and excessive pressure is also the major cause that leads to leakages. The average leakage for Western Europe recorded at $0.53 \mathrm{~m}^{3} / \mathrm{hr} . \mathrm{km}$ and for other country is $1.3 \mathrm{~m}^{3} / \mathrm{hr} . \mathrm{km}$ [4]. Hence, leakage management is required to reduce water loss and improve both distribution efficiency and economically [7].

Losses in water network happen as early as before it been treated which it happens in raw water pipe line. This shows that leakages waste the natural resource. The cost of raw water, its transportation to water treatment plant by gravity or pumping and these losses shall be the primary economic loss.

Leakages in treated water distribution network are also risk public health. Leak openings shall open to contamination and it shall lead to disease. This is important notes that the water operator need to undergo water sampling activities to ensure the treated water supply are in good manner and satisfy the World Health Organisation requirement and parameters. Even in leak occurrence all this parameter need to sample frequently so that the water supplied is saving to be consumed. It notes that, to repair and restore leak requires a huge economics investment but this is important to ensure that the water operators will have a good return on investment as well as the consumer satisfaction.

Leaks assessment studies have been conducted to determine the exact amount of water loss and total losses. This is followed by the development of leak detection method with the purpose of detecting and finding leakage. Leak detection is important to ensure that leaked locations can be identified and thus facilitate repair work to be carried out. However, leak detection technology is increasingly sophisticated today.

Many effort, investment and study have been out to identify and finding leak. As many countries the consumers are being the eyes of the water operator to log a complaint after seeing any leak occurs in the water network system. Many studies have been carried out and leak detect evolved by time.

Dividing the water network into an organised metered area is a popular approach in water network management. This subdividing is known as establishing the District Metered Area (DMA) for big scale network and District Metered Zone (DMZ) for a smaller distribution network. This zone separation is conducted by establishing the water network boundary via one single feeder and Zero Pressure Test (ZPT) testing need to be conducted. Upon successfully obtaining the zone boundaries the water network baseline shall be established. Therefore, leakages index shall be established in every zone that has been created. Leakages index shall be computed review and further improved. By managing this, the NRW level by each zone can be established. This shall help water operators to further improve their water network. With DMA, the leakage has been reduced over $30 \%$ in 25 years' time [5]. It's not just UK using this method even in other countries as well [5, 6].

There are many methods in identifying leakage of pipes. The most popular method to detect water leaks for household is using sound signal recordings [8]. By applying this method, the data of recording, sampling and processing need to be obtained. This recent year, leak detection using leak correlators are widely used. This device has proven to be most efficient and accurate than using the conventional method which by using listening sticks. Correlators can be pinpointing leakages for any pipe condition and material. Leak noise correlator also can determine the size of the leak in the water distribution network.

Thermography for leak detection is another technology that can determine leak in water distribution network. The wet condition via leakages shall changes the thermal soil temperatures. This condition shall allow thermography leak detection to pinpointing the leak. Nevertheless, this technology is not widely used in most countries due to climate exchange and whether condition.

Wireless method for leakage and burst detection is using Wireless Sensor Networks using Transform Analysis [9]. Wireless sensors are also the latest technology method that in the market for leak detection. Wireless sensors are equipped with its own sensors and algorithm software. These sensors are communicating with its software and the basic fundamental of leakage detection method 
are based on sounding and transient sampling through the pipeline. The most suitable time to correlate with during midnight where no noise interruption by the traffic vehicle.

Real-Time Leak Detection in Water Distribution Networks is another type of technology to help the detection of leak in short of time. New functional algorithm developed by water expertise via new technology to identify leak based on pressure measurement [10]. Sensors build in SCADA's and RTU's are install every max $3 \mathrm{~km}$ each to establish pressure management, transient sounding and flow measurement module. All this data is then being processed by its intelligent software to forecast the supply stability. This analytical software is also able to forecast the anomalies in the water distribution network and its will trigger the water operator to act before the burst or leak happens. Real time-based monitoring will give a lot of hand to water operator to monitor large area of water reticulation system. The leak or burst is projected and forecasted in real time approach [11]. Hence, this application will assist the water operator to plan their maintenance on the water distribution network.

The objective of this study is to review and provide the information the leak detection method in water distribution system that can help the water industry to choose the suitable method to reduce the frequent and number of leakages. Leakages assessments need to be considered to evaluate on the investment spend over leak repair.

\section{Leak detection by sounding and acoustic devices}

Leak detection method via sounding and acoustics devices are most popular among the water operator though out the world. The most efficient way to detect leak is via sounding $\mathrm{n}$ using acoustic devices [13]. These devices such as listening sticks and ground microphone detect the leak by the sound (noise) or vibration induced by the pressurised water distribution network [30]. The vibration sound will travel and transmitted over a significant distance depends in the type, size and aging of the pipe. The water operator crew will listen and pointing the exposed pipe asset such as valves, fire hydrant, meter point and many more [31]. Crew is also roughly bracket leak in water reticulation system by listening the exposed contact point as derived. The suspected leak then pinpointed on the ground surface above the pipeline at very 1-meter interval.

Three major steps are most common in detecting leak using sound signal record [8]. This step is known as recording, storing and process the sound signal. Easy installation via non-intrusive equipment will be installed and giving the accurate result that will help to identify the leak. This concept is using the sounding and acoustic fundamental to identify the leaks.

Segmental steel bar with approximately 1-meter length are known as listening stick is widely used by the water operator crew. This steel bar is extendable for its length that can help the crew to sound at deeper surrounding area. Listening stick are design to transmit noise amplication that produced by underground leak [13]. This stick is also equipped with a brass diaphragm within chamber to improve the stick sensitivity. Listening stick is made of chrommed plated steel it is ideal for crew to differentiate between static or leak that introduced the noise. Listening stick is now available with an electronic model that helps the crew to make a better sound and to find more underground leak effectively. The usage is recommended is because:
i. Portable
ii. Low cost
iii. Easy to use
iv. Less maintenance
v. Life long span

Different pipe material, size and aging will indicate different leak noise. This shall illustrate in (Figure 1). Audible sound which due to water pressure is illustrated in (Figure 2). The transmittal sound effect from different pipe material is illustrated in (Figure 3). Elements that contain in leakages noise are as follows:

i. Impact sound

ii. Friction water against pipe 
iii. Water flow

iv. Vibration sound

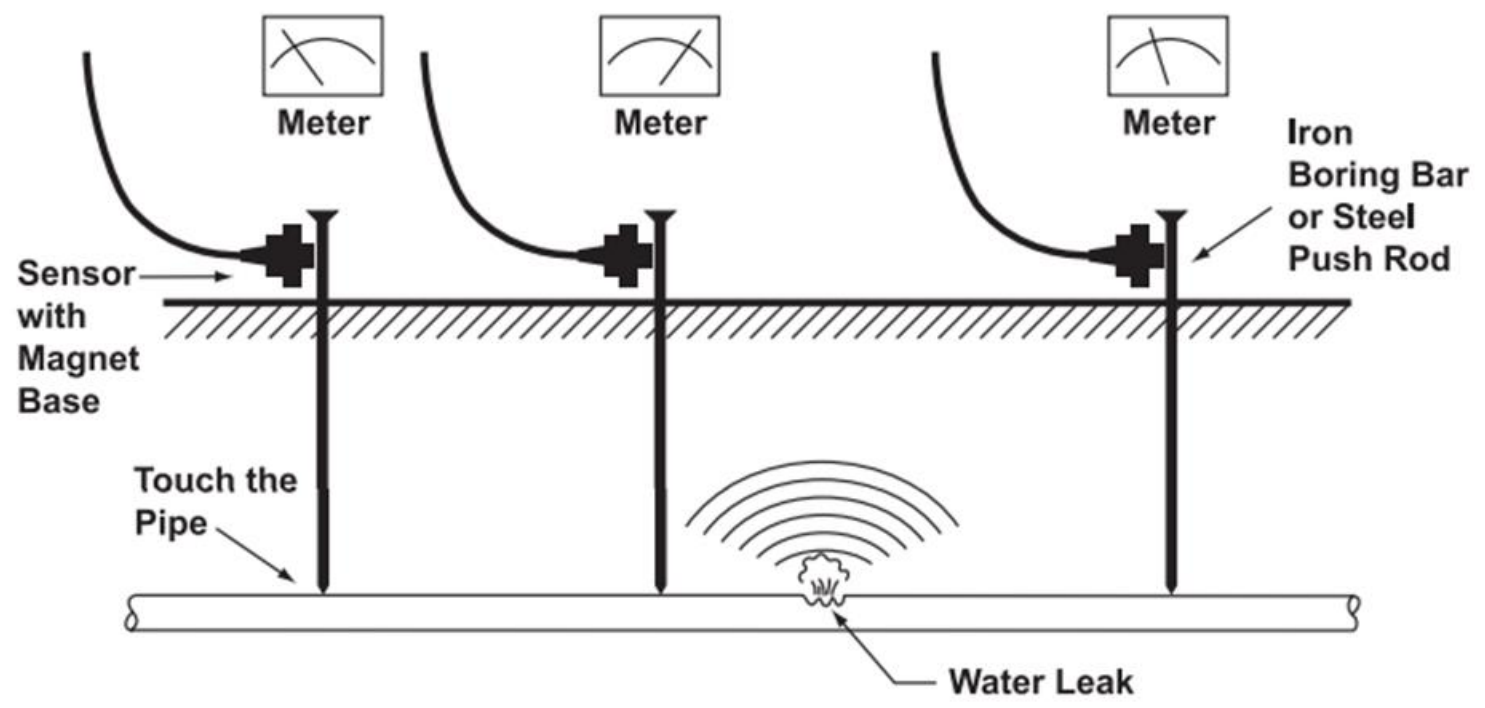

Figure 1. Water leaks create different sounds. (Source: http://www.subsurfaceleak.com)

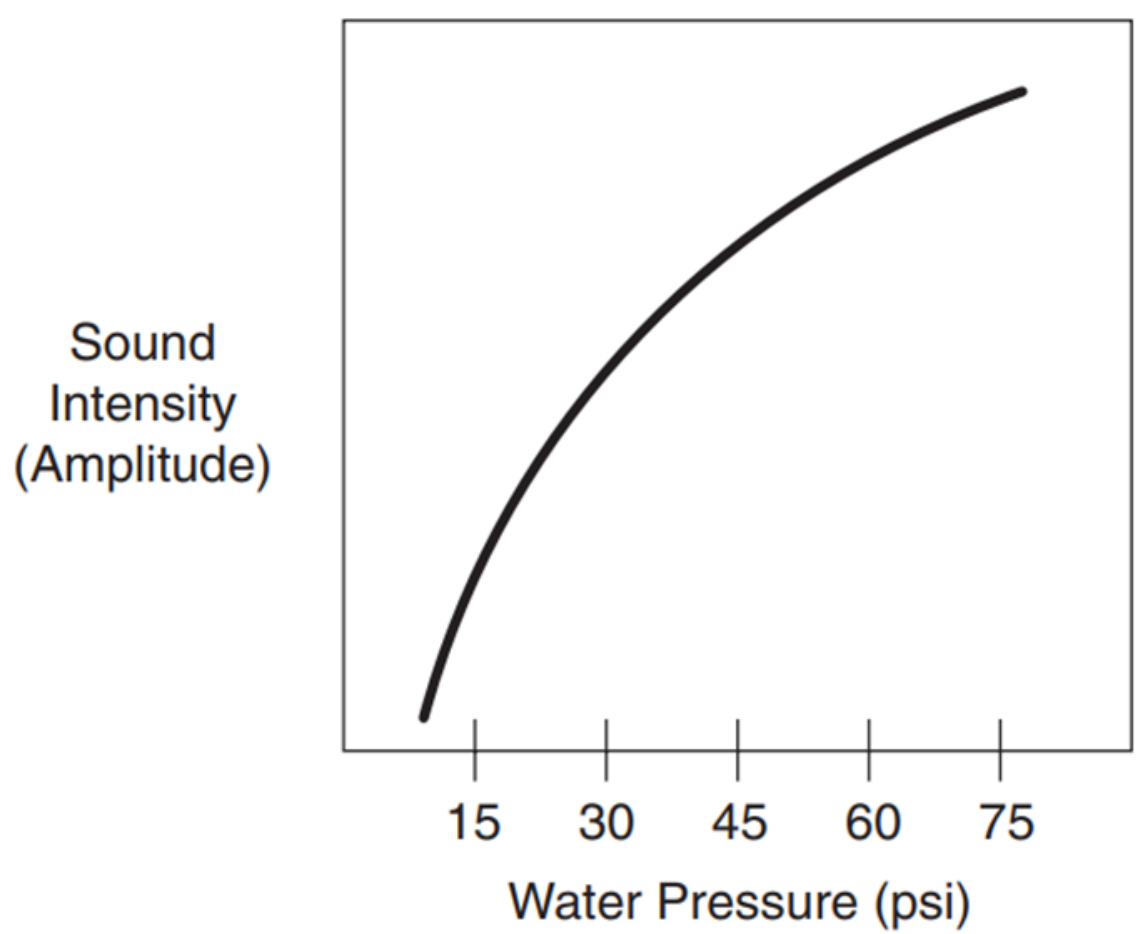

Figure 2. Sound intensity increases with water pressure (Source: http://www.subsurfaceleak.com) 


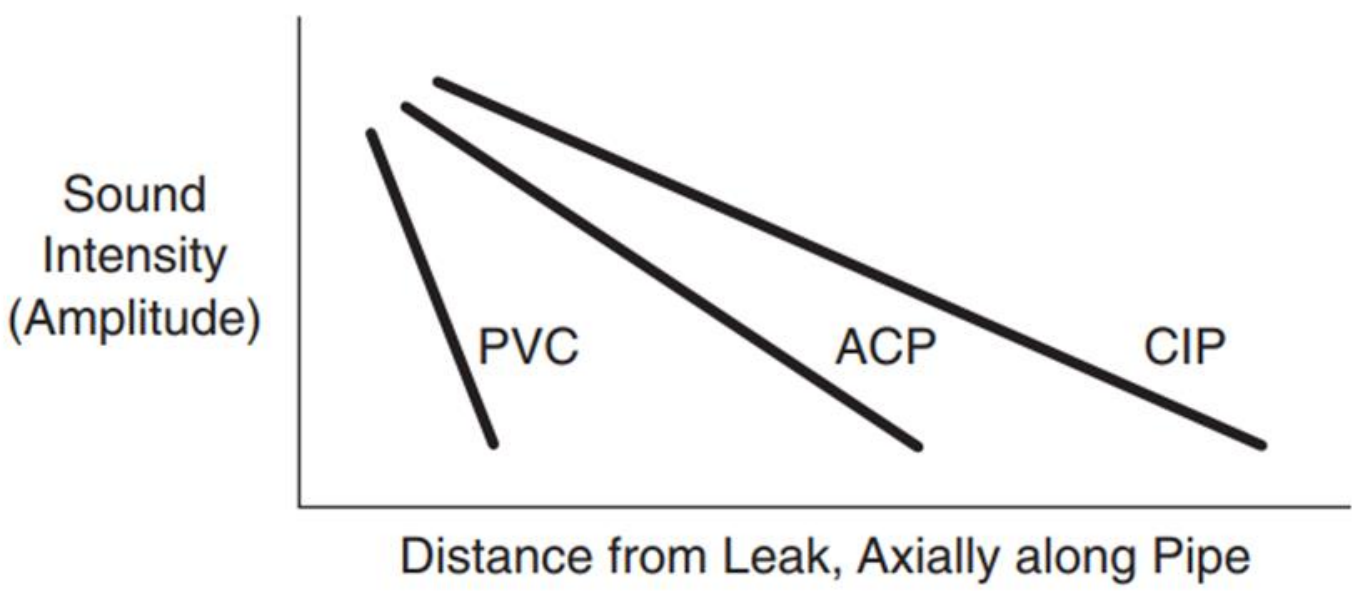

Figure 3. Various pipe materials transmit sound differently. (http://www.subsurfaceleak.com)

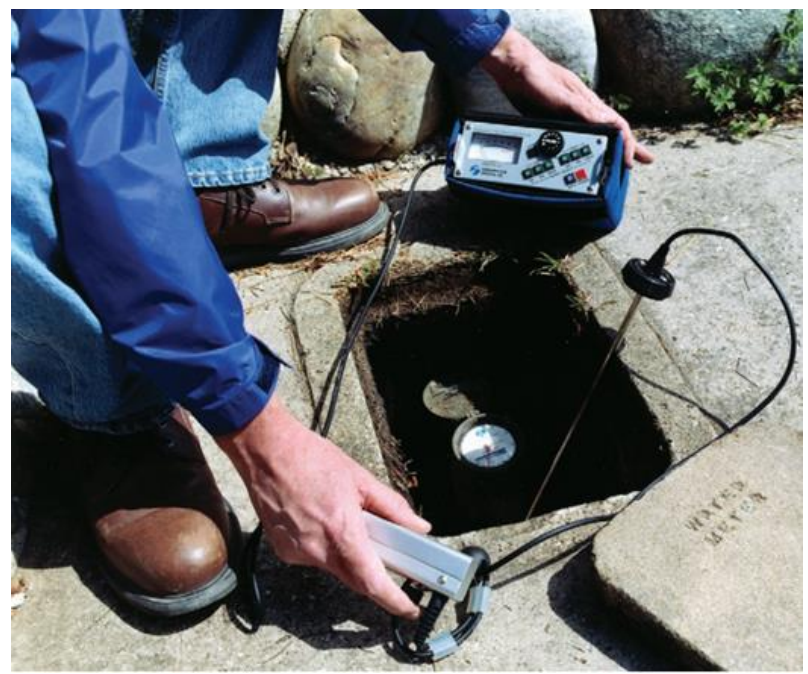

Figure 4. Leak survey at meters (http://www.subsurfaceleak.com)

Table 1: The advantages and disadvantages using acoustics leak detection method

\begin{tabular}{ll}
\hline Advantages & Disadvantages \\
\hline Cost effective and cheap & $\begin{array}{l}\text { Requires experienced and } \\
\text { finding leak techniques } \\
\text { Reliable and less } \\
\text { maintenance } \\
\text { Practical and user friendly }\end{array}$ \\
$\begin{array}{l}\text { Maximum pointing depth } 1.5 \mathrm{~m} \\
\text { Indoors and outdoors use }\end{array}$ & $\begin{array}{l}\text { Difficulties when at the grass } \\
\text { Bround } \\
\text { nest leak finding only during at }\end{array}$ \\
$\begin{array}{l}\text { Accurate at the most possible } \\
\text { leak detected } \\
10 \text { to } 15 \text { years life span }\end{array}$ & \\
\hline
\end{tabular}




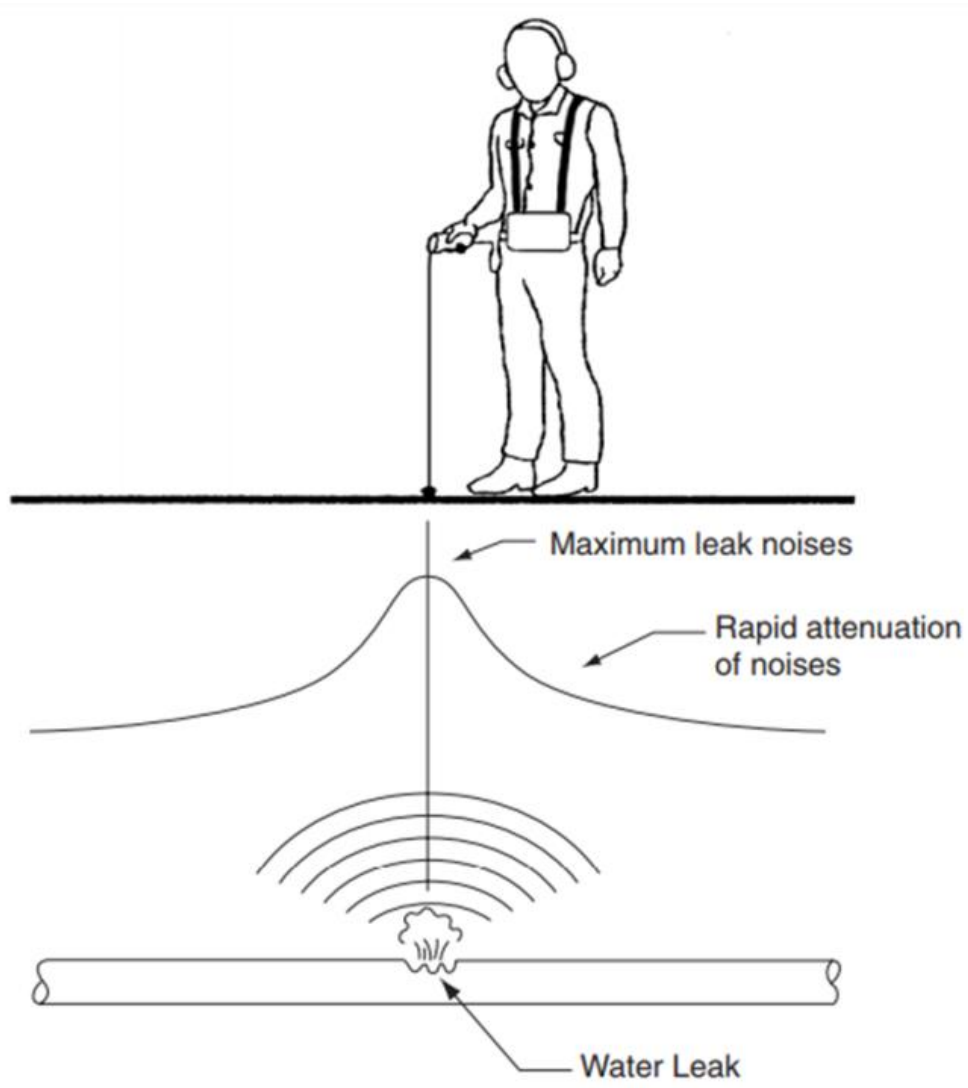

Figure 5. Water leak pinpointing. (Source: http://www.subsurfaceleak.com)

\section{Leak detection using sensors}

A leak noise correlator sensor has proven its workability. It has proven to be more effective and efficient to compare with listening stick and ground microphone. Noise correlator sensor shall be install to any exposed pipe material such as valve, hydrant and meter point with interval of max of $100 \mathrm{~m}$ to correlate the leak. Sensor will detect the noise created by the leak and pointed at the actual length of the leak located. The crew then will mark the location and planned to fix the leak.

Time domain reflectometry (TDR) based system in detecting pipe leakage has been developed [14, 15]. The system massively carried out by the largest European Water Operator. This system uses sensors element (SE) such as wires that are mounted along the buried pipeline [16]. SE is buried with a pipe and when necessary it can be verifying the presence of leakage. As soon as the pipe part is equipped with SE, the water operator can identify presence of leakage in five-minute time. This TDR leak detection system accelerates localization of leakage and helped water company to run more tracking campaign. Figure 6 show schematization of the TDR-based leak detection apparatus. To determine the location of the leak, the operator connects the TDR instrument to the point of connection point $\mathrm{K}$ which can be accessed through the manhole or through proper inspection. Basically, SE will be representing a transmission line, whereas TDR traffic can be spread.

This method not only use for detecting the water leakage but also for characterization of electronic devices [17, 18]; for landslide monitoring [19]; for liquid level measurements [20-22]. The wireless sensor used in leak detection also use in military application due to efficiency of the sensor [23]. 


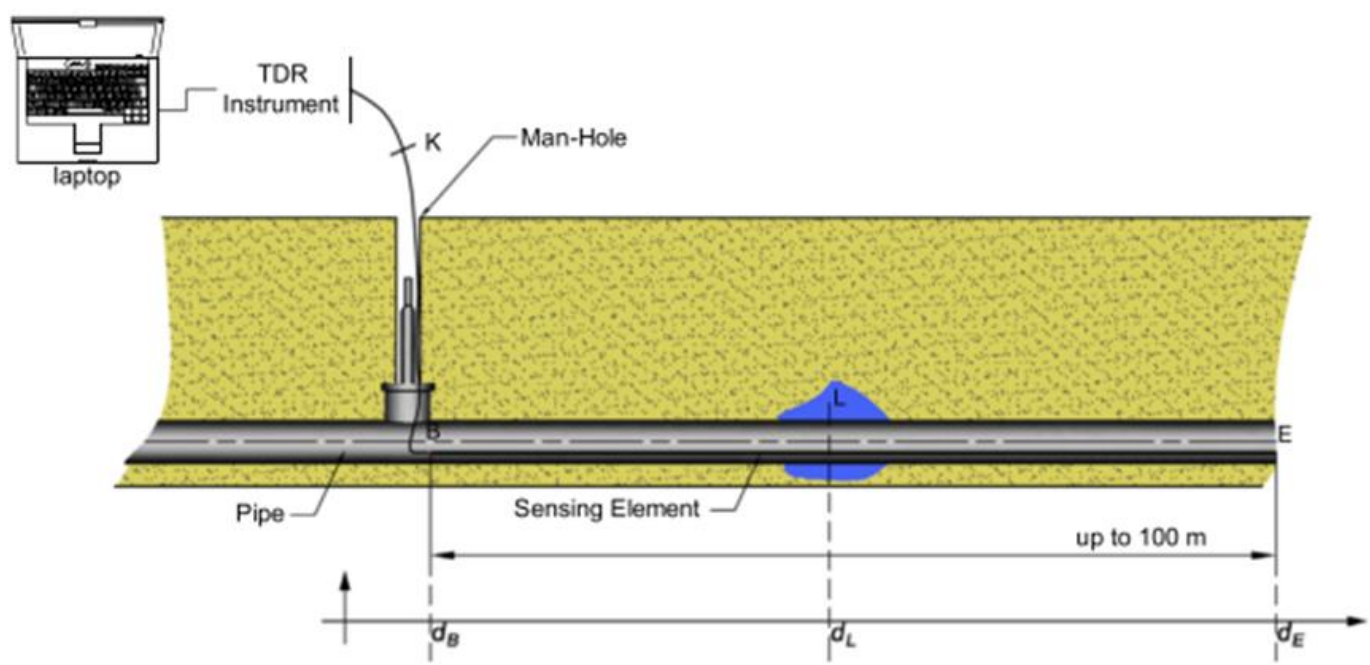

Figure 6. Schematization of the TDR-based leak detection apparatus [16]

The use of accelerometer in each valve of the connection valves can also be used in detecting pipe leakage [12]. Vibration signal obtained from each measuring device analysed using machine vector support (SVM), decision results (DT) and Naïve Bayes (NB) to identify the index monitoring of each sensor. Leaks are identified when the received signal increases above the threshold. The accuracy of this method promises accuracy of up to $98.25 \%$ to differentiate broken and unbreakable conditions. This method is a new approach to assist in early detection of leakages and prevent leakage from happening worse.

Leak detection using acoustic correlation was developing to compare the acoustic and vibration sensor at between two valve connections [13]. Figure 7 show the noise from a leak can be pinpointed and located. The technique used to determine the delay time between signal sensors using the correlation crosslinking function $12 \operatorname{Rx}_{1} x_{2}(\tau)$ between the two signals measured $x_{1}(t)$ and $x_{2}(t)$.

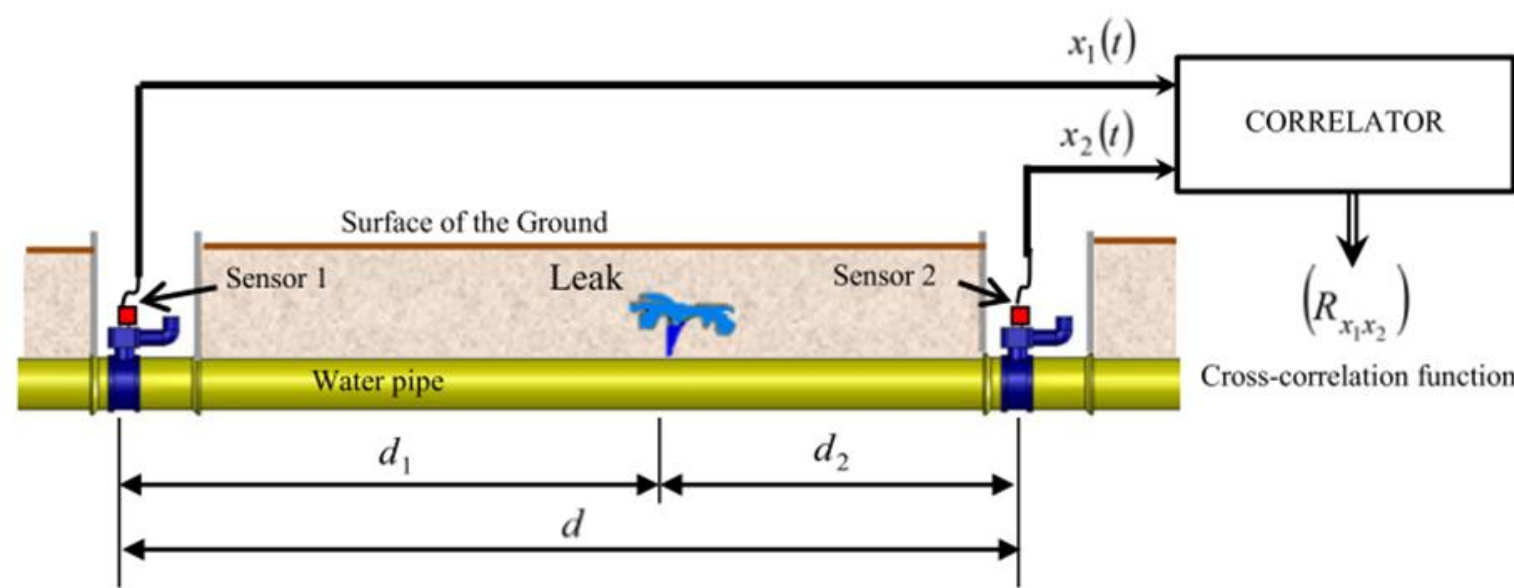

Figure 7. Schematic of leak detection in a buried plastic water pipe using acoustic/vibration signals with a leak in between the two sensors [13]. 


\section{Real Time leak Detection Method}

Leak Detection via real time based in water distribution networks is another type of technology to help the detection of leak real time analysis. New set of technology incorporate with sensors has been invented. Real time leak detection method equipped with SCADA's and RTU's to transmit real time data and process by analytical software that manages to predict the water supply system stability. Sensors are equipped with flow measurements, transient sounding sampling and pressure records. Pressure losses ratio is developed and incorporated as part of the algorithm to project and analysed potential leak that can happen [10]. Head loss ratio is where the head differences between both sensors can be describe as leak or burst. This anomaly then being analysed by analytical tool and diagnose the losses characteristic and define the possible leak that could happen in the water network system.

Algorithm which has created the possibilities, probabilistic projection was develop using Bayesian demand methodology [11]. The model then established to create a projection and probability statistic where the possibilities leak could happen. In any pipe burst condition it will trigger the water operator to take urgent action due to reduction of pressure and excessive of flow in water network system. One of the latest technology and methods used is online burst detection using the kalman filter and hydraulic modelling $[25,26]$.

Adaptive particle filters to identify leakages have long been used especially in determining gas leakage $[27,28]$. The flow value in all type of pipe was able to determine with particle base algorithm [29].

Wireless sensors are also available solution for leak detection. It is also can be converted as real time monitoring sensors that help the water operator monitoring the condition of their water network. The redundancy of the sensors and integration between on to another will allow continuous monitoring and project the leak before it happens.

Wireless sensor networks using pressure-based detection method and transform analysis was developing to fasten the detection [24]. This method uses a wave-based wave technique which is paired with an analysis to reach the location of the detector whose title is sudden. Temporary pressure signal is used to carry over the information. The use of wavelet analysis to determine pressure effect pattern in the pipeline due to leakage. This technique provides more the accuracy of $90 \%$ in identifying pipe leakage. The detection algorithm is divided into 3 parts as shown in the figure 8 . There are 2 main blocks of block A for data collection while block B for local interference module. The sensor node used in this circuit is a Waspmote type where six nodes have been used and 4 nodes are set as $\mathrm{n} 1, \mathrm{n} 2, \mathrm{n} 3$ and $\mathrm{n} 4$ as well as two are cluster head nodes. 


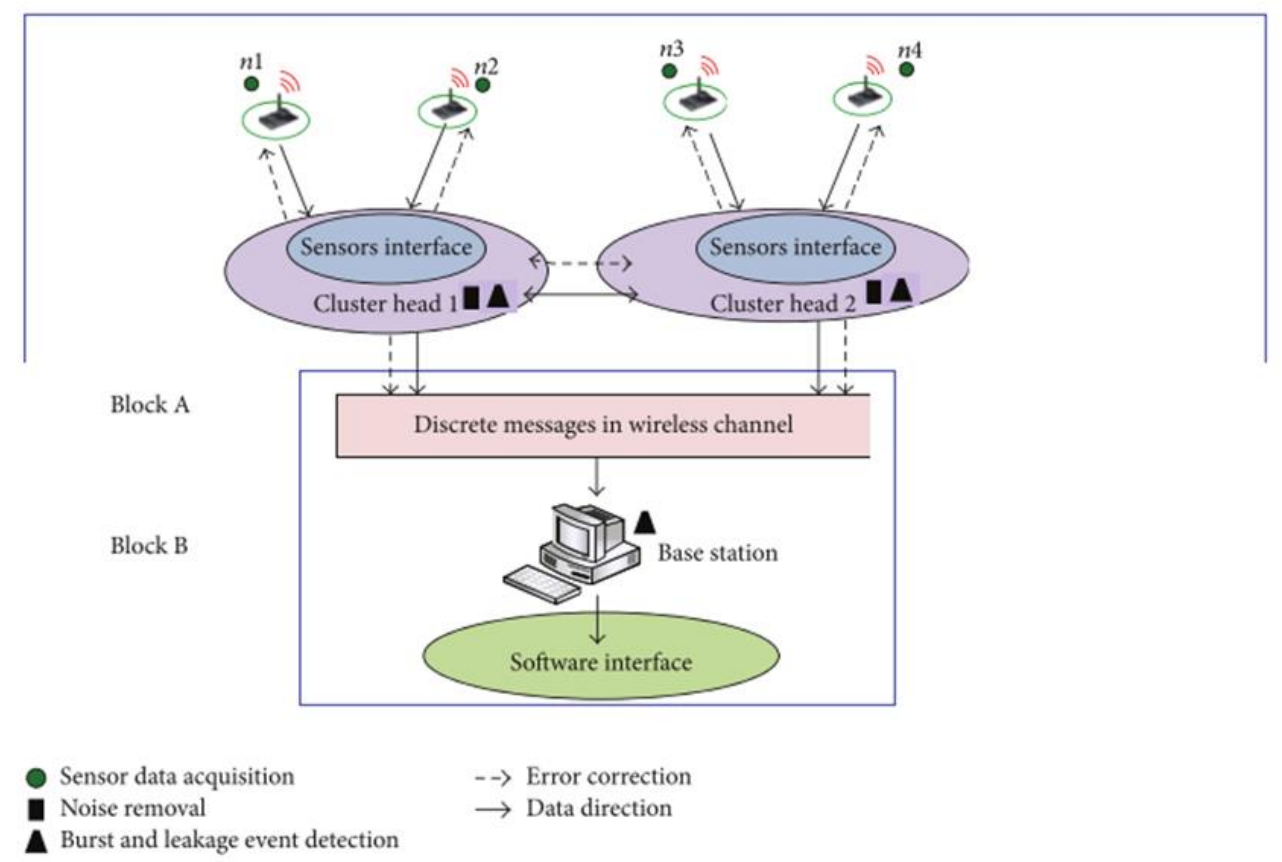

Figure 8. Distributed processing architectural layout [23]

The wireless smart sensor network is the solution to determine the location of the underground pipe leak without having to go to the scene [9]. Easy installation of pressure measurement sensors are established using non-invasive method. Two sensors shall communicate, and it will alarm if there is sudden change of pressure profile that lead to burst incident.

\section{Conclusion}

Many countries are faced the problem of leak detection and burst. To overcome this problem the suitable method is requiring ensuring the detection can be performing in short time. This important to make sure the loss of treated water can be minimized. The water company should take more action to ensure the water can be distributed to the consumer without delaying so much time. That's why leak detection is important to fasten the repairing of the leakage pipe. The evolution and early prediction of leak development is to ease the water operator to maintain their water supply network into the best and most practical condition. The higher the number of leakages the worst the water network system will be, and higher Non-Revenue Water shall be recorded. Any unfind leakages shall lead wastages and contributes non-economic values to the any water operators. Preserving the water is the responsibility of all which the quality of good water must be passed to another generation. Therefore, the integrity of the water supply network must be handled as best as could and must be in the optimum operational condition. The technology evolved as time goes and the leakages detection must ride and in tandem of the coming current technologies. In the perspective on efficiency, the operators are measured by the percentage of Non-Revenue Water performance percentages. The lower it is the most efficient it will be. By having efficient leak detection method in the water supply network, it will reduce the percentage of NRW's level by locality. Therefore, investing on leakages detection technology it will give return on investment in average of 5 years averagely. The most important, water is the greatest creations that need to be preserved by any mankind. Ending this review, finding and repairing the leak are the responsibility of all to ensure the sustainability if water resources to be passed to the next generations. 


\section{References}

[1] A. Balut, A. Urbaniak, Management of Water Pipeline Networks Supported by Hydraulic Models and Information Systems, 12th International Carpathian Control Conference (ICCC), 25-28 May, Velke Karlovice, Czech Republic. 2011, pp. 16-21

[2] R. Mckenzie, Z.N. Siqalaba, W.A. Wegelin, The State of Non-Revenue Water in South Africa, WRP Consulting Engineers (Pty) Ltd, WRC Report No. TT 522/12, 2012.

[3] Rogers, D. 2014. "Leaking Water Networks: An Economic and Environmental Disaster." $\begin{array}{lllll}\text { Procedia } & \text { Engineering } & 70 . & \text { Elsevier } & \text { B.V.: }\end{array}$ https://doi.org/10.1016/j.proeng.2014.02.157.

[4] Gao Quan-chao. Study on Network Leakage Region Determination and Leakage Estimation in Urban Water Supply system [D]. Taiyuan, Taiyuan University of technology, 2008

[5] P. Gomez, F. Cubillo, F. Mart'in, Comprehensive and efficient sectorization of distribution networks, Procedia Engineering 70 (2014) 753-762.

[6] A. Di Nardo, M. Di Natale, G. F. Santonastaso, V. G. Tzatchkov, V. H. Alcocer-Yamanaka, Water network sectorization based on graph theory and energy performance indices, Journal ofWater Resources Planning and Management 140 (2013) 620-629.

[7] Jing, Kang, and Zou Zhi-Hong. 2012. "Time Prediction Model for Pipeline Leakage Based on Grey Relational Analysis." Physics Procedia 25 (50778009). Elsevier Srl: 2019-24. https://doi.org/10.1016/j.phpro.2012.03.344.

[8] Seyoum, Solomon, Leonardo Alfonso, Schalk Jan Van Andel, Wouter Koole, Ad Groenewegen, and Nick Van De Giesen. 2017. "A Shazam-like Household Water Leakage Detection Method." Procedia Engineering 186.

[9] Sadeghioon, Ali, Nicole Metje, David Chapman, and Carl Anthony. 2014. "SmartPipes: Smart Wireless Sensor Networks for Leak Detection in Water Pipelines." Journal of Sensor and Actuator Networks 3 (1): 64-78. https://doi.org/10.3390/jsan3010064.

[10] Ishido, Y., and S. Takahashi. 2014. "A New Indicator for Real-Time Leak Detection in Water Distribution Networks: Design and Simulation Validation." Procedia Engineering 89. Elsevier B.V.: 411-17. https://doi.org/10.1016/j.proeng.2014.11.206

[11] Hutton, Christopher, and Zoran Kapelan. 2015. "Real-Time Burst Detection in Water Distribution Systems Using a Bayesian Demand Forecasting Methodology." Procedia Engineering 119 (1). Elsevier B.V.: 13-18. https://doi.org/10.1016/j.proeng.2015.08.847.

[12] Samer El-Zahab, Eslam Mohammed Abdelkader, Tarek Zayed, An accelerometer-based leak detection system, Mechanical Systems and Signal Processing,Volume 108,2018, Pages 276291,ISSN 0888-3270

[13] Almeida, F. C.L., M. J. Brennan, A. T. Paschoalini, P. F. Joseph, and Y. Gao. 2017. "On the Signum Function and Its Effect on Acoustic Correlation for Leak Location in Buried Plastic Water Pipes." Procedia Engineering 199. Elsevier B.V.: 1344-49. https://doi.org/10.1016/j.proeng.2017.09.346.

[14] Cataldo A, Cannazza G, De Benedetto E, Giaquinto N. Experimental validation of a TDR-based system for measuring leak distances in buried metal pipes. Progr. Electromagnet. Res. 2012; 132:71-90.

[15] Cataldo A, Persico R, Leucci G, De Benedetto E, Cannazza G, Matera L, De Giorgi L. Time domain reflectometry, ground penetrating radar and electrical resistivity tomography: a comparative analysis of alternative approaches for leak detection in underground pipes. NDT \& E Int. 2014; 62:14-28. http://dx.

[16] Cataldo, Andrea, Egidio De Benedetto, Giuseppe Cannazza, Giuseppina Monti, and Christian Demitri. 2016. "Accuracy Improvement in the TDR-Based Localization of Water Leaks." Results in Physics 6

[17] Cataldo A, Monti G, De Benedetto E, Cannazza G, Tarricone L, Catarinucci L. A comparative analysis of reflectometry methods for characterization of antennas. In: 2008 IEEE I2MTC 
international instrumentation and measurement conference proceedings; 2008, p. 240-43. http://dx.doi.org/10. 1109/IMTC.2008.4547038.

[18] Chen M-K, Tai C-C, Huang Y-J. Nondestructive analysis of interconnection in two-die BGA using TDR. IEEE Trans Instrument Measur 2006;55(2):400-5

[19] Gueguen E, Bentivenga M, Colaiacovo R, Margiotta S, Summa V, Adurno I. The verdesca landslide in the Agri Valley (Basilicata, southern Italy): a new geological and geomorphological framework. Nat Hazards Earth Syst Sci 2015;15(11):2585-95.

[20] Nemarich C. Time domain reflectometry liquid level sensors. IEEE Instrument Measur Mag 2001;4(4):40-4. http://dx.doi.org/10.1109/5289.975464.

[21] Cataldo A, Cannazza G, De Benedetto E, Giaquinto N, Trotta A. Reproducibility analysis of a TDR-based monitoring system for intravenous drip infusions: Validation of a novel method for flow-rate measurement in IV infusion. In: MeMeA 2012-2012 IEEE symposium on medical measurements and applications, proceedings, 2012, pp. 203-7. http://dx.doi.org/10.1109/ MeMeA.2012.6226673.

[22] Cataldo A, Piuzzi E, De Benedetto E, Cannazza G. Experimental characterization and performance evaluation of flexible two-wire probes for TDR monitoring of liquid level. IEEE Trans Instrument Measur 2014;63(12):2779-88. http://dx. doi.org/10.1109/TIM.2014.2318393.

[23] Al-Kadi, Tariq, Ziyad Al-Tuwaijri, and Abdullah Al-Omran. 2013. "Wireless Sensor Networks for Leakage Detection in Underground Pipelines: A Survey Paper." Procedia Computer Science 21. Elsevier Masson SAS: 491-98.

[24] Rashid, Sidra, Saad Qaisar, Husnain Saeed, and Emad Felemban. 2014. "A Method for Distributed Pipeline Burst and Leakage Detection in Wireless Sensor Networks Using Transform Analysis." International Journal of Distributed Sensor Networks 2014. https://doi.org/10.1155/2014/939657.

[25] Okeya, I., Z. Kapelan, C. Hutton, and D. Naga. 2014. "Online Burst Detection in a Water Distribution System Using the Kalman Filter and Hydraulic Modelling." Procedia Engineering 89. Elsevier B.V.: 418-27. https://doi.org/10.1016/j.proeng.2014.11.207.

[26] Jung, D., and K. Lansey. 2014. "Burst Detection in Water Distribution System Using the Extended Kalman Filter." Procedia Engineering 70. Elsevier B.V.: 902-6. https://doi.org/10.1016/j.proeng.2014.02.100.

[27] A. Benkherouf, and A. Y. Allidina, "Leak detection and location in gas pipelines," IEE Proceedings (Control Theory and Applications), vol. 135, no. 2, March, 1988, pp. 142-148.

[28] M. Liu, S.Zang, and D. Zhou, "Fast leak detection and location of gas pipelines based on an adaptive particle filter," International Journal of Applied Mathematics and Computer Science, vol.15, no.4, pp.541-550, 2005

[29] Anjana, G. R., K. R. Sheetal Kumar, M. S. Mohan Kumar, and Amrutur Bharadwaj. 2015. "A Particle Filter Based Leak Detection Technique for Water Distribution Systems." Procedia Engineering 119 (1). Elsevier B.V.: 28-34.

[30] H.V. Fuchs, R. Riehle, Ten Years of Experience with Leak Detection by Acoustic Signal Analysis, Applied Acoustics Vol. 33, (1991), 1-19.

[31] Brennan, M. J.Karimi, M.Almeida, F. C.L.De Lima, F. Kroll.Ayala, P. C. Obata, D. Paschoalini, A. T.Kessissoglou, N. 2017 "On the role of vibro-acoustics in leak detection for plastic water distribution pipes”. Procedia Engineering 199 (2017) 1350-1355 